\title{
Relationships between body size and physical abilities in elite female tennis players
}

\author{
Anna Skorodumova and Igor Baranov \\ Russian Tennis Federation, Moscow, Russia.
}

\begin{abstract}
This paper studied the relationships between anthropometry and physical fitness indicators that affect elite female tennis players' training process planning. Bodyweight and height were measured as well as aerobic and anaerobic lactic capabilities, and the physiological indicators determined. Results showed reliable relationships between the anthropometric and functional fitness indicators and the players' competitive performance. It was concluded that monitoring the average weight relative to the height of female tennis players can assist in the improvement of the players' performance through changes in the training process, specifically by relating the weight and height indicators with the strengths and weaknesses of the players' tactical patterns.
\end{abstract}

\begin{abstract}
Key words: physical and functional fitness, total body sizes, elite female tennis players, the competitive performance results

Received: 13 June 2021

Accepted: 15 July 2021

Corresponding author: Anna Skorodumova. Russian Tennis Federation, Lutzhnetskaya Nab 8, Moscow.Email: ibaranov1805@ mail.ru
\end{abstract}

\section{INTRODUCTION}

To improve the training process, it is necessary to precisely understand the requirements that a high-level athlete must meet in a particular sport. Specifically, research in tennis have identified the parameters of the external indicators of the energy system demands during high-performance female players competitive matches (Skorodumova et al., 2019) and the requirements for their physical and functional fitness (Skorodumova et al., 2019).

For an optimal implementation of the training process, it is necessary to determine the relationships between physical and functional fitness indicators and the result of the performance in competitions $(\mathrm{CP})$ and to clarify and prioritise the physical abilities that contribute to maximise the results. In this context, researchers and coaches should pay considerable attention to aspects such as the total body sizes, the determination of height, weight, and their corresponding ratios in female tennis players.

The external indicators that define the energy system demands during competitive tennis matches are well known (Ivanova, 2010; Naumko, 1996). However, there was a common view that the best tennis players were characterised by being taller and slimmer, i.e., anthropometric indicators, of which the mass and height index is important (Naumko, 1996) than the non-so successful players. Therefore, the lack of research that contributes to clarify the relationships between the total body sizes and the CP, as well as the indicators of the functional and physical fitness, justifies the need for this study.

The objective of the study is to determine the relationships between some indicators that evaluate the total body sizes, functional and physical abilities of high-performance female tennis players and the results of their competitive performance. The specific research questions of the study are the following: 1. Determine the total body sizes of Russian high-performance female tennis players; 2 . Determine the functional and physical fitness of Russian high-performance female tennis players; 3 . Determine if there are statistical correlations between total body size indicators and the result of Russian high-performance female tennis players' competitive performance; 4 . Determine if there are statistical correlations between the total body size indicators of Russian high-performance female tennis players and the physical and functional fitness indicators; and 5. Compare the total body sizes indicators of leading female tennis players in Russia with similar indicators of leading female tennis players in the world.

\section{METHODS}

The total body sizes, functionality, and physical fitness were determined as part of a stage-by-stage comprehensive testing. Body weight measurement conducted using medical scales, the accuracy of which was up to $10 \mathrm{~g}$. Athletes stood on the middle of the scale platform, having previously removed shoes and extra clothes, and were on it in a standing position, without moving, until the moment of weight measurement. Body height was measured by an easel height meter in a standing position from the apex point to the support. The athletes' initial position was the main stand - the back is straight, the heels together, the knees are straightened, the hands along the body. Based on these measurements, two indicators were calculated: the mass-height index (MHI Kettle 1; $\mathrm{MHI}=\mathrm{m} / \mathrm{H}$ ) and the body mass index (BMI Kettle 2; $\mathrm{BMI}=\mathrm{m} / \mathrm{H} 2$, where $\mathrm{m}$ is the weight of the athlete, and $\mathrm{H}$ is the body height).

The functionality measures were conducted as follows: the aerobic capabilities were determined during a treadmill 
running, with a stepwise increasing load every 2 minutes to overflowing. During the test, the heart rate was taken and the exhaled air was analysed using an automatic gas analyser 'Metalyzer- 2,' to determine the different physiological indicators. The anaerobic lactic free capabilities were measured using a 6 seconds of maximum intensity work on a cycle ergometer. The determination of the players' physical fitness was carried out using specific developed tests widely used in Russia in studies with tennis players (Skorodumova et al., 2013; Skorodumova et al., 2018).

The statistical analysis used included the determination of averages and quadratic deviations, the calculation of Pearson correlation coefficients and the linear rationing of obtained values.

\section{Sample}

Data from 41 top female tennis players (age average 17 y.o. $\pm 3,41$ ) who played for the national teams of the Russian Tennis Federation were used in this study.

\section{RESULTS AND DISCUSSION}

Table 1 includes the total body sizes of the players in the sample and the indicators of the functional capabilities of the energy supply systems and the physical fitness obtained.

\section{Table 1}

Indicators of the total body sizes of the top female tennis players in Russia $(n=41)$.

\begin{tabular}{lcccc}
\hline Indicators & $\begin{array}{c}\text { Body } \\
\text { height }(\mathrm{cm})\end{array}$ & $\begin{array}{c}\text { Body } \\
\text { weight }(\mathrm{kg})\end{array}$ & $\begin{array}{c}\mathrm{MHI}(\mathrm{g} / \\
\mathrm{cm})\end{array}$ & $\begin{array}{c}\mathrm{BMI}(\mathrm{kg} / \\
\mathrm{m} 2)\end{array}$ \\
\hline Mean value & $174.6 \pm$ & $64.27 \pm$ & $367.92 \pm$ & $21.06 \pm$ \\
\pm Standard & 5,54 & 6,21 & 29,99 & 1,62 \\
deviation & & & & \\
\hline
\end{tabular}

MHI: mass-height index (Kettle index 1); BMI: body mass index (Kettle index 2).

The calculations showed that the correlation of the total body size indicators with the competitive performance results was $11.1 \%$. Table 2 includes the statistical correlations of the indicators and their impact on the relation between the total body sizes and the competitive performance.

\section{Table 2}

Statistical correlations between the indicators that characterise the total body sizes of female tennis players and their competitive performance $(C P)(n=41)$.

\begin{tabular}{lcccc}
\hline $\begin{array}{l}\text { Anthropometric } \\
\text { indicators }\end{array}$ & $\begin{array}{c}\text { Body } \\
\text { height }(\mathrm{cm})\end{array}$ & $\begin{array}{c}\text { Body } \\
\text { weight }(\mathrm{kg})\end{array}$ & $\begin{array}{c}\mathrm{MHI} \\
(\mathrm{g} / \mathrm{cm})\end{array}$ & $\begin{array}{c}\mathrm{BMI} \\
(\mathrm{kg} / \mathrm{m} 2)\end{array}$ \\
\hline $\begin{array}{l}\text { Statistical } \\
\text { correlation } \\
\text { with CP, \%, }\end{array}$ & 14,9 & 31,3 & 29,7 & 24,1 \\
$\begin{array}{l}\text { p-value }<0.05 \\
\text { Priority }\end{array}$ & 4 & 1 & 2 & 3 \\
\hline
\end{tabular}

MHI: mass-height index (Kettle index 1); BMI: body mass index (Kettle index 2).

The results indicated that the greatest correlation with the total body sizes values were obtained with the players' weight, not their height, as previously suggested (Naumko, 1996). Apparently, the conclusion made by the author is related to the height of male tennis players. In our study, the women's body height indicator showed the smallest correlation. In fact, the height of the female tennis players ranked one and two in the world is 166 and $168 \mathrm{~cm}$ respectively, and the average height of world's 10 top female tennis players is $174.6 \mathrm{~cm}$ (min 166 - $\max 182$ ).

The second correlation was shown by the mass-height index and its significance to the total body sizes takes 2nd place. In this context, it has been considered that according to this mass-height index, it is logical to calculate the energy expenditures of the body (Naumko, 1996). The third correlation was shown by the body mass index (BMI or Kettle index 2), which allows to calculate the ratio of a person's mass and height. According to the World Health Organization's (WHO) interpretation of the BMI indicators, which includes rating scales, the indicators of female tennis players (mean $21.06 \mathrm{~kg} / \mathrm{m} 2$ ) are on the average values of the 'Norm' scale $(18.5-24.99 \mathrm{~kg} / \mathrm{m} 2)$.

The following indicators showed statistically significant correlation coefficients that were considered at the significance value $p<0.05$. The bodyweight index correlated with the body height at $r=0.599$, with the mass-height index at $r=0.953$ and with the body mass index at $r=0.748$. The body height correlated with the mass-height index at $r=$ 0.331 , and the mass-height index correlated with the body mass index at $r=0.913$ (Figure 1).

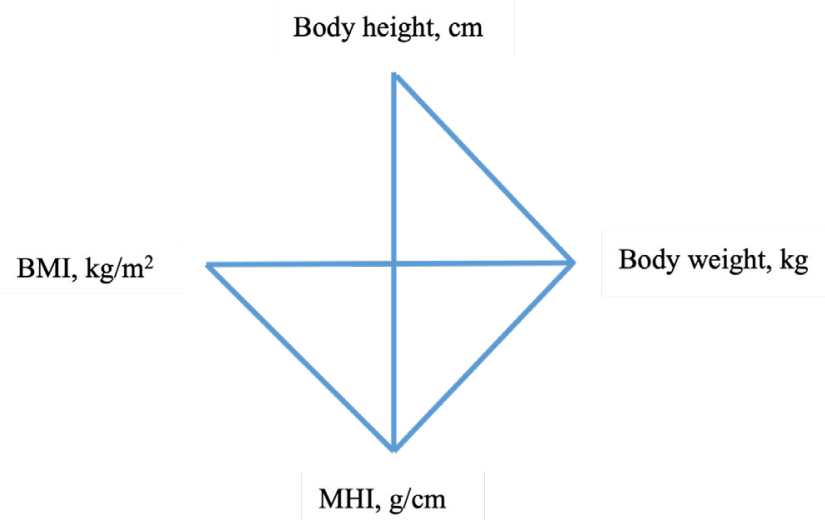

Figure 1. Correlation of anthropometric indicators. MHI: mass-height index (Kettle index 1); BMI: body mass index (Kettle index 2).

Thus, the two indexes, the bodyweight and the mass-height index, correlated with all the analysed indexes.

The body height index and the body mass index did not correlate and had the least contribution to the significance of the total body sizes. Thus, regardless of the height, players should monitor very carefully their weight and mass-height index. None of these indicators had a statistically significant correlation with the outcome of the competitive performance. However, body height, body weight, and mass height index had a statistically significant correlation with power indicators (VO2max, O2Pulse, MVV), and with aerobic performance indicators (VO2AT), which have a reliable correlation with the outcome of the competitive performance. Bodyweight showed a significant correlation with another indicator of the $\mathrm{CP}$ efficiency, the oxygen consumption at the aerobic threshold level. The body mass index showed a significant correlation with VO2AT, VO2max, and O2Pulse (Table 3). 
Table 3

Statistical correlations of the total body sizes and the functional capabilities indicators. $(n=41, p$ value $<0.05)$

\begin{tabular}{lcccccc}
\hline Indicators & $\begin{array}{l}\mathrm{VO}^{2} \mathrm{AET} \\
(\mathrm{ml} / \mathrm{min})\end{array}$ & $\begin{array}{l}\mathrm{VO}^{2} \mathrm{AT} \\
(\mathrm{ml} / \mathrm{min})\end{array}$ & $\begin{array}{l}\mathrm{VO}^{2} \mathrm{max} \\
(\mathrm{ml} / \mathrm{min})\end{array}$ & $\begin{array}{l}\mathrm{O}^{2} \mathrm{Pulse} \\
(\mathrm{ml} / \mathrm{b})\end{array}$ & $\begin{array}{l}\mathrm{MVV} \\
(\mathrm{l} / \mathrm{min})\end{array}$ & $\begin{array}{l}\mathrm{T} \text { peak } \\
\text { power } \\
(\mathrm{s})\end{array}$ \\
\hline $\begin{array}{l}\text { Body } \\
\text { height }\end{array}$ & - & 0.427 & 0.525 & 0.530 & 0.428 & 0.558 \\
$\begin{array}{l}\text { Body } \\
\text { weight }\end{array}$ & 0.461 & 0.586 & 0.687 & 0.635 & 0.445 & 0.510 \\
$\begin{array}{l}\text { Mass- } \\
\text { height } \\
\text { index }\end{array}$ & - & 0.529 & 0.615 & 0.553 & 0.367 & - \\
$\begin{array}{l}\text { Body } \\
\text { mass } \\
\text { index }\end{array}$ & - & 0.370 & 0.412 & 0.346 & - & - \\
\hline
\end{tabular}

VO2AET: oxygen volume consumption at the anaerobic threshold; VO2AT: oxygen volume consumption at the aerobic threshold; VO2max: maximum oxygen volume consumption; O2Pulse: the volume of oxygen consumed by the body per heartbeat; MVV: maximal voluntary ventilation; $T$ peak power: time to reach the peak power.

Table 3 shows only those functional performance indicators that showed a statistically significant correlation with the competitive performance. Of all 13 indicators of the anaerobic productivity, the indicator of time to maximum power showed a reliable correlation with the competitive performance. Body height and weight showed a reliable correlation with this indicator. Bodyweight and mass-height index showed a positive correlation with the maximum power, although it did not show a correlation with the competitive performance, but surely had, albeit insignificant, some influence.

All indicators excluding the body mass index showed a significant correlation with the glycolytic endurance index, and the body height and the weight showed significant correlation coefficients with the vertical jump with both the left and the right foot.

The absence of correlations between the total body size indicators and the indicators of agility suggests that agility does not depend on the athlete's height and weight. Therefore, being very high, a female tennis player can also be very coordinated and vice versa.

Comparing the total body sizes of the leading Russian female tennis players with similar indicators to the world's top 10 female tennis players, it can be stated that there are no reliable differences in any of the indicators (Table 4).

Table 4

Total body sizes of leading female tennis players in Russia and the world.

\begin{tabular}{lcccc}
\hline \multirow{2}{*}{ Tennis player } & \multicolumn{4}{c}{ Indicators } \\
\cline { 2 - 5 } & $\begin{array}{c}\text { Body } \\
\text { height }(\mathrm{cm})\end{array}$ & $\begin{array}{c}\text { Body weight } \\
(\mathrm{kg})\end{array}$ & $\begin{array}{c}\mathrm{MHI}(\mathrm{g} / \\
\mathrm{cm})\end{array}$ & $\begin{array}{c}\mathrm{BMI}(\mathrm{kg} / \\
\mathrm{m} 2)\end{array}$ \\
\hline $\begin{array}{l}\text { From Russia, } \mathrm{n}= \\
\text { 41, mean value }\end{array}$ & 174,6 & 64,27 & 367,92 & 21,06 \\
Min-max & $167-180,1$ & $58-70$ & $\begin{array}{c}337,9- \\
397,9\end{array}$ & $19,4-22,7$ \\
$\begin{array}{l}\text { Top 10 tennis } \\
\text { players in the } \\
\text { world, mean value }\end{array}$ & 174,6 & 64,40 & 368,47 & 21,11 \\
Min- max & $166-182$ & $57-72$ & $335-411$ & $19,72-$ \\
\end{tabular}

MHI: mass-height index (Kettle index 1); BMI: body mass index (Kettle index 2).
The weight, the height of the players and all indexes are very similar between the group of the top 10 female tennis players in the world and the other Russian female tennis players. The data obtained indicated that the total body sizes of the players correlated with the competitive performance around $10 \%$, which is not decisive in deciding the competitive potential. The important aspects related to the total indicators of female tennis players are their weight and their weight-toheight ratio (i.e., mass-height index). The weight should not be much more than $70 \mathrm{~kg}$, while the mass-height index should be $340-400 \mathrm{~g} / \mathrm{cm}$. The total body indicators also showed a statistically significant correlation with the indicators of aerobic performance power and efficiency.

When in competition, female tennis players should be efficient, i.e., being fast, moving quickly in all directions, and hitting powerful shots. In some situations, female tennis players perform the movements of sprinters, in others those of the high and long jumpers. Moreover, hitting a serve in tennis has similarities with the throws. Since there are optimal values of total body indicators that characterize each sport, we compared the average values of leading Russian female tennis players with similar indicators of 10 leading female athletes in sprint, high jump, long jump, and javelin throw (Table 5).

\section{Table 5}

Indicators of total body sizes of leading Russian female tennis players and 10 strongest female athletes in sprinting, high and long jumps, and javelin throwing.

\begin{tabular}{lccccc}
\hline $\begin{array}{l}\text { Total size, } \\
\text { (mean } \\
\text { value) }\end{array}$ & $\begin{array}{c}\text { Running } \\
100 \mathrm{~m}\end{array}$ & $\begin{array}{c}\text { High } \\
\text { jump }\end{array}$ & $\begin{array}{c}\text { Long } \\
\text { jump }\end{array}$ & $\begin{array}{c}\text { Javelin } \\
\text { throwing }\end{array}$ & $\begin{array}{c}\text { Russian female } \\
\text { tennis players, } \\
\mathrm{n}=41\end{array}$ \\
\hline $\begin{array}{l}\text { Body } \\
\text { height } \\
\text { (cm) }\end{array}$ & 168.7 & 180.5 & 173.8 & 177.0 & 174.6 \\
$\begin{array}{l}\text { Body } \\
\text { weight } \\
\text { (kg) }\end{array}$ & 58.7 & 61.1 & 62.4 & 75.0 & 64.27 \\
$\begin{array}{l}\text { MHI (g/ } \\
\text { ?m) }\end{array}$ & 347.9 & 338.5 & 359.0 & 423.7 & 367.92 \\
$\begin{array}{l}\text { BMI (kg/ } \\
\text { m2) }\end{array}$ & 20.8 & 18.8 & 20.86 & 24.1 & 21.06 \\
\hline
\end{tabular}

Abbreviations: $\mathrm{MHI}$, mass-height index (Kettle index 1); BMI, body mass index (Kettle index 2).

The body height of the female tennis players takes an average position. They were shorter than high jumpers and javelins but taller than long jumpers and sprinters. The average body weight of the female tennis players and their index values was second only to javelin throwers. The average square deviation from the average body weight was more than $6 \mathrm{~kg}$. Female tennis players' bodyweight had the greatest contribution to the relation between total body sizes and CP results and ranged from 56 to $77 \mathrm{~kg}$, with the athletes who had a weight less than average being close to high jumpers and shortdistance runners on this indicator. Furthermore, they were lighter than spear-throwers. The same can be said about the mass-height index.

We can suppose that the total body sizes of the players may have an impact on the different tactical patterns they use during competition. Table 6 presents data on two female tennis players' total body sizes, which are among the top ranked players in the world, which clearly use different tactical patterns. 


\section{Table 6}

Total body sizes of two high-performance female tennis players that use different tactical patterns.

\begin{tabular}{lcccc}
\hline \multirow{2}{*}{$\begin{array}{l}\text { Female } \\
\text { tennis } \\
\text { players }\end{array}$} & $\begin{array}{l}\text { Body height } \\
(\mathrm{cm})\end{array}$ & $\begin{array}{l}\text { Body weight } \\
(\mathrm{kg})\end{array}$ & MHI (g/cm) & BMI (kg/m2) \\
\cline { 2 - 5 } 1. S. Williams & 175 & 72 & 411,4 & 23,51 \\
2. S. Halep & 168 & 60 & 357,1 & 21,26 \\
\hline
\end{tabular}

MHI: mass-height index (Kettle index 1); BMI: body mass index (Kettle index 2).

Tennis player 1 plays powerful shots, trying to finish off the points as quickly as possible with her aggressive strategy. Her anthropometric data are closer to those of the javelin throwers. Tennis player 2 moves easily around the court and dominates the point using active movements which allow her to usually win points longer than 10 seconds. Her anthropometric data are closer to those of the best short-distance runners and jumpers in the world. These relationships provide further directions for future studies and, if the assumptions are confirmed, it will be necessary to make the necessary changes to the training process.

\section{PRACTICAL APPLICATIONS}

Previous research suggested that height was a key aspect for high-performance female and male tennis players to achieve a high performance. Our study suggests that for highperformance Russian female tennis players, the weight of the players would be more relevant than their height. Our results show that at this high level the average weight of the players was $64.27 \mathrm{~kg}$, and the average height was $174.6 \mathrm{~cm}$. Therefore, coaches should carefully monitor these relationships by providing the optimal combination of an appropriate diet with the adequate training loads to increase performance.

Based on the results obtained in this study, it was possible to assume that the weight and height of the players have an influence on the tactics applied during match play. In comparison with lighter and shorter players, heavier and taller players seem to use powerful attacking groundstrokes and volley with the intention to finish off the point as quickly as possible. These anthropometric features are similar to those that happen in disciplines such as javelin throw. Results have also shown that lighter and shorter players can also play attacking shots by easily moving around the court in rallies lasting more than $10 \mathrm{~s}$. The features of these female tennis players are more similar to those of the 10 best short-distance runners and jumpers in the world.

\section{CONCLUSIONS}

The results of this study emphasise the importance of monitoring the average weight relative to the height of the female tennis players' and to develop tactical patterns that reflect the strengths and weaknesses of the players based on these indicators by implementing the necessary changes in the training process that will facilitate their performance.

\section{ACKNOWLEDGMENTS}

The authors would like to express their gratitude to the Russian Tennis Federation management officials for their understanding of the importance and complexity of the control of the training of the tennis players, to all players that took part in the testing procedures performed at the laboratory, to all the staff from the laboratory, and to the institute's management for their assistance in organising and conducting tests.

\section{REFERENCES}

Ivanova, G.P. (2010). Tennis. Growing up the champion. St. Petersburg, National state University of Physical Culture, Sports and Health named after P.F. Lesgaft.

Naumko, A.I. (1996). Competitive performance of highly level tennis players and the methods of its assessment [dissertation]. Moscow: RSUPCSYT.

Skorodumova, A.P., Baranov, I.S., Tarpishcheva, A.R., Semenova, S.D., and Tarpischev, P.S. (2019). Competitive activity of high level female tennis players on courts with different types of surfaces. Science and sports: modern trends, 8(4):66-70.

Skorodumova, A.P., Tchaikovskaya, O.O., Baranov, I.S., Tarpishcheva, A.R., Tarpishchev, F.Sh., and Abdrakhmanova, D.G. (2019). The external load of tennis players in matches on different surfaces. Topical scientific and methodological problems of the training of athletes in game sports: Materials of the All-Russian Congress, RSUPCSYT. Moscow; 291-294.

Skorodumova, A.P., Baranov, I.S., and Semenova, S.D. (2019). Structure of physical and functional fitness of high-level female tennis players. Theory and practice of physical culture and sports;12:38-40.

Skorodumova, A.P. Trukhachev, A.A. Kuznetsova, OV and Baranov, I.S. (2013). Tests for the assessment of physical and functional fitness of tennis players and model characteristics of their readiness. Moscow, Federal State Budgetary Institution Federal Center of Sports Reserve Preparation.

Skorodumova, A.P., Baranov, I.S., Kuznetsova, O.V., and Semenova, S. D. (2018). Control of the physical fitness of 6-14 year old tennis players. Moscow.

Copyright (c) 2021 Anna Skorodumova and Igor Baranov

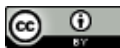

This text is under a Creative Commons BY 4.0 license

You are free to Share - copy and redistribute the material in any medium or format - and Adapt the content - remix transform, and build upon the material for any purpose, even commercially under the following terms:

Attribution: You must give appropriate credit, provide a link to the license, and indicate if changes were made. You may do so in any reasonable manner, but not in any way that suggests the licensor endorses you or your use. 